\title{
A Canadian S\&T strategy for pest management methods
}

\author{
by J. Peter Hall
}

\begin{abstract}
The outcome from a stakeholder workshop on pest management methods describes the elements of a national S\&T strategy to address the issues of ecological integrity, sustainable management of forests and the need for collaboration in forest stewardship. The workshop looked beyond current problems to prepare the forest sector for the challenges of sustainable and competitive wood supply in the face of new and varied demands on the forest coupled with the anticipated impacts of climate change. Workshop participants emphasized the need for forest pest management as an essential component of sustainable forest management and identified several themes and goals to achieve sustainability. Participants developed a vision for our forests that incorporates social and economic sustainability, of ecologically healthy forests providing fibre, while demonstrating that we live in harmony with our forest environment.
\end{abstract}

Key words: integrated pest management, ecological integrity, forest ecosystem science

\section{RÉSUMÉ}

Les conclusions d'un atelier sur les méthodes de contrôle des ravageurs décrivent les éléments d'une stratégie nationale en matière de science et de technologie répondant aux enjeux d'intégrité écologique, de développement durable des forêts et de la nécessité d'établir une collaboration relativement à l'intendance des forêts. L'atelier a été au-delà des problèmes actuels afin de préparer le secteur forestier à répondre aux défis reliés à l'approvisionnement durable et compétitif en matière ligneuse face aux nouvelles demandes variées portant sur les forêts en tenant compte des conséquences anticipées des changements climatiques. Les participants à l'atelier ont mis l'accent sur le contrôle des ravageurs forestiers comme étant une composante essentielle de l'aménagement forestier durable et ont identifié quelques thèmes et objectifs pour atteindre la durabilité. Les participants ont élaboré une vision de nos forêts qui incorpore la durabilité sociale et économique, des forêts écologiquement en santé qui procurent des fibres tout en démontrant que nous vivons en harmonie avec notre environnement forestier.

Mots clés : aménagement intégré des ravageurs, intégrité écologique, sciences des écosystèmes forestiers

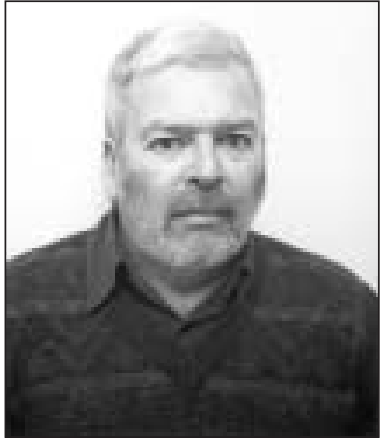

J. Peter Hall

\section{Introduction}

This article summarizes the outcome of a workshop on Pest Management Methods S\&T Strategy organized by the Canadian Forest Service (CFS) on 18-19 November, 2004 in Ottawa. The workshop was attended by representatives of federal, provincial, academic, and industrial organizations. It was designed to look beyond today's problems to ensure that the forest sector is ready to meet challenges of the next decades so that Canada will have a sustainable and competitive wood supply and ecological integrity of its forests. Invited presentations included perspectives from forest pest management research, ecological integrity in National Parks, management of gypsy moth in the United States, the regulation of pest control products, and from forest industry. This paper presents the results of the workshop and outlines the role of stakeholders and strategic approaches to pest management.

Canada's forests are central to its environmental, social and economic well-being. Forests filter the air we breathe and the water we drink and provide habitat for plants and animals. Forests offer a multitude of spiritual and recreational values. Several hundred, mainly rural, communities are primarily or wholly dependant on forests. Nearly half of the productive forest is managed commercially for forestry and contributes substantially to our national wealth, providing over 360000 jobs and more than $\$ 44.7$ billion to our balance of trade. Canada needs to demonstrate that its forests are managed according to accepted criteria of sustainability in conformance with international agreements to which we are a signatory.

In modern resource management, pest management must be integrated with socioeconomic and ecological imperatives to support Sustainable Forest Management (SFM). Effective pest management is particularly critical where forests are intensively managed with long-term investments in place. Of the many organisms that form part of the forest ecosystem,

${ }^{1}$ Science Advisor, Natural Resources Canada - Canadian Forest Service, 580 Booth Street, Ottawa, Ontario. E-mail: phall@nrcan-rncan.gc.ca 
few are designated as "pests"; it is only when insects compete directly for the resource with humans that they are designated as pests. The first impacts are economic — lack of available fibre and trade barriers associated with regulated areas and products. The environmental and social consequences soon follow the economic ones.

Pest management is not a threat to biodiversity; rather, it is needed to help maintain and protect biodiversity. Several tree species are currently under threat from pests; white pine, ash, elm, and butternut. Pest management is important to support international trade through detection and management of invasive species, which can act as potential trade barriers. Integration of forest pest management with SFM adds quality and value to wood fibre and maintains the marketability of forest products. Pest management tools are best used in conjunction with ecological imperatives; for example, adaptive forest management practices such as variable retention silviculture.

Implementation of a pest management strategy within SFM requires an adequate understanding of the ecology of forests and pests, how they interact at the tree, stand, and landscape level. A suite of proven and innovative tools for pest detection, forecasting and management that limit impact on non-target organisms, strategies to support markets, and public support for these measures are all necessary. Forest mangers, as much as anyone, want to avoid the need to react suddenly to adjust to events that could have been anticipated.

The issues with which forest managers are dealing are complex and require a multi-disciplinary response because resource management takes place in an environment across a range of scales in space and time. It is this breadth of scale that imparts resiliency to forest ecosystems and enables them to respond to disturbances. The goal of forest pest management is to advance the science and practice of pest management and integrate it with sustainable forest management objectives so that the ecosystem remains resilient to other natural and anthropogenic disturbances. A pest management strategy must therefore:

- integrate all elements of the pest management issue,

- respond to and anticipates events,

- allow for continuous improvements,

- recognize the responsibilities for forest management by all stakeholders, and

- maintain desired forest values including a competitive timber supply.

\section{The Current Situation}

The forest mosaic reflects past disturbances from wildfire, pests, harvesting and other events. For instance, old-growth and decadent stands have developed as a result of fire suppression, and large-scale monocultures have developed after harvesting caused a change in species. Disturbances are intrinsic to forests; they drive forest succession and so are essential for promoting nutrient cycling, stand re-establishment and forest resiliency. This combination of disturbance and resiliency are necessary elements of forest sustainability and renewal in natural systems. Historic management policies aimed at sustaining timber yields have suppressed wildfires and interrupted successional patterns resulting in unusually extensive areas of decadent stands that are vulner- able to pests; the bark beetle problem in British Columbia is an unfortunate example of this process. Forest managers, nevertheless, have to deal with forest ecosystems as they find them and they find them altered to a greater or lesser degree from "pristine" states.

Both public and private forests are in the public eye and transparency in forest management activities now drives forest management policies. Demands for a range of forest values is now the norm and the principal one is that of ecological integrity, defined as a state of optimal ecosystem development. Considerations of integrity include energy input, available water, nutrients, colonization history, geographic location, native species, supporting processes, and the ability to reproduce. This concept is being applied in all forests whether production forests, conservation forests or urban forests.

The control of insects, diseases and weeds in crop systems has long existed in agriculture. In forestry, the development of DDT and techniques of aerial spraying were used in insect control in the 1950s and 1960s, primarily for the eastern spruce budworm. Following the publication of Rachel Carson's Silent Spring in 1962, public attitudes began to change and eventually these persistent broad spectrum chemical products were banned. New, naturally-occurring, more host-specific products such as Bt (Bacillus thuringiensis), which only affected lepidopteran species, replaced these older pesticides. This product has widespread use but it too has come under attack from a public that doubts its benign health effects and recognizes its impacts on non-target organisms.

The economic implications of pest outbreaks are large and without protection from insects, diseases and weeds; gains made through intensive forest management can be lost. During 1982-1987, losses caused by insects were estimated at 51 million $\mathrm{m}^{3}$ annually, or one-third of the annual harvest. Although less visible - and more difficult to quantify than insect or disease damage - losses caused by competing vegetation can be equally significant, particularly in intensively managed plantations. Without protection from these damaging factors, gains expected from more intensive forest management will be lost.

These losses have adverse impacts on the forest environment and social consequences for resource-dependant communities. A few pests reduce growth and yield, form, and survival of trees below a biological and economic threshold that varies according to the economic investment and value of the forest. In forests where conservation or protection are the primary values and the economic concerns are less, the activities of insects and diseases are regarded more as "acceptable" components of the ecosystem. Where fibre is the primary management goal, pests have more serious social and economic impacts. Decisions on whether to undertake pest management activity then depends on these biological and economic thresholds.

Forest managers have a dilemma in that past forest management practices have reduced the resiliency of forests. Forest managers have followed the engineering approach in trying to achieve "efficiency" by using pesticides, but this direct control often did not improve the underlying ecological conditions that generated the pest problem in the first place. The alternative is to try and understand the desired state, and then manage processes at appropriate temporal and 
spatial scales. An integrated approach to pest management means reliance on ecological approaches of control and less emphasis on direct measures. Integrated pest management (IPM) builds on the accumulated knowledge and technology, considers all forest values, and treats forests as living systems. This approach will enable us to anticipate and adapt to pest problems so that reliance on reactive approaches is minimized.

Ecosystems operate at a range of spatial and temporal scales, each having a unique structure, composition and function and are often structured from the top down. In complex systems, cross-scale processes are important because they influence resilience, stability and dynamics and consequently sustainability. The ecological state that we call "forest health" is the expression of cross-scale processes at work. Pest management activities will take place in the context of a changing climate which will exacerbate some problems and mitigate others in a forest already disturbed and altered by human activities. For example, forest management techniques will rely more extensively on silviculture and stand management techniques to minimize pest losses.

\section{Pest Management Needs}

There are many tools for pest management at our disposal; we have a long history of forest research, we have good scientific and operational capabilities, and forestry is an important facet of Canadian life. Given these assets, we have many of the tools necessary for a national strategy. The workshop participants identified the following major issues.

\section{A basic knowledge of forest ecology, management systems and pests}

Improved knowledge is a sine qua non of forest pest management. Much research in the past has not been directed toward a regional- or landscape-level goal of sustained yield and has failed to incorporate the concept of forest ecosystem-level pest management. Enhanced knowledge of basic forest ecology is essential to understand the processes at work in forests. Knowledge of successional patterns and forest development at the stand and landscape level is necessary. This knowledge must then integrate pest management with forest management activities. For instance, in the development of direct chemical approaches, biological or bio-rational substances need to be as host-specific as possible with minimal nontarget impacts on the environment. These substances include pheromone mating disruptors, release of sterile male insects/parasitoids and entomopathogens. Support is necessary from forest management agencies to provide products for regional short-term use in managing pests. Science programs need to identify target areas, cost-efficiencies, and application technologies.

Biological control using predators and parasites can be used to effect a "natural" collapse of insect outbreaks. The CFS has had a long history of classical biological insect control in the management of pests - the European spruce sawfly, larch casebearer, larch sawfly, satin moth, winter moth, the European pine shoot moth, and mountain ash sawfly. Longer-term silvicultural techniques are also worth developing as they are usually ecologically benign. The conversion of balsam fir stands to more insect-tolerant spruces is a good example of this approach.
The ability to monitor, evaluate and detect potential pest problems Pest management requires efficient methods of early identification, detection and forecasting to determine which pest is likely to be damaging and at what level. Then, computerbased decision support systems can integrate these forecasts with wood supply information and other values such as wildlife habitat to provide the necessary information for forest managers in decision-making. Workshop participants identified the need for a national forest pest survey supported by the CFS to emphasize national science standards and reporting - while partnering with the provinces as implementing agencies to support this process. The need for historical and current data in detecting and monitoring pest outbreaks remains undiminished for effective pest management and also for monitoring species biodiversity and climate change impacts.

Climate change will be an important factor in pest management in the future and managers will be operating in a continually changing environment. Forest management will have to accommodate changing utilization standards as harvesting activities begin to exploit marginal boreal forests. Climate changes will include a gradual warming coupled with "surprises" of increasing frequency. Ranges of pests, both native and exotic, are expected to expand northward as the climatic conditions governing the range of tree species change. Forest ecosystems have never experienced the combination of warming and pest impacts.

\section{The need for adequate science support and a coordinated approach by stakeholders}

Managers require the scientific infrastructure to support an effective program of pest management. At the same time, the resource demand for research must compete with many demands. Many of the operational demands in pest management are cyclical and so resources tend to diminish when there is no perceived problem; when the problem is obvious, the ability to respond consists of what is available. The development of innovative techniques takes time. The need to manage resources efficiently demands that there be a close and coordinated approach by all stakeholders; the public, forest managers, landowners and industry.

\section{Ecological integrity and the integration of pest management with SFM}

The biggest challenge is knowledge acquisition by science coupled with the necessary understanding and implementation. The balancing between natural and human disturbances, ecological integrity, resilience of the system, and forest uses is complex. Forest managers have to resolve demands from among conflicting priorities. A strong basis of science, up-to-date information management, collaboration among many agencies, government and non-government, and stable funding are all required for success. The issues are interrelated and change at varying rates and directions; changes that occur whether we do anything or not. Disturbance a measurable change to ecosystem productivity, dynamics or successional paths - has impacts on resilience, which is the capacity for a system to absorb shocks and recover. Managers have the capacity to absorb these demands, but it takes a cultural change to "look at these things differently." Pest management must be geared to the life span of the tree crop, which is 
longer than many planning horizons require. Too often, pest management tries only to deal with pests after they become problems and/or as an entity separate from forest management. Problems are the usual outcome.

\section{Role of Stakeholders}

The federal government through its departments and agencies has a mandate to promote sustainability by research on forest issues. Federal agencies - the Pest Management Regulatory Agency (PMRA) and the Canadian Food Inspection Agency (CFIA) - have responsibilities relating to health and safety of pesticides and the protection of forests from invasive alien species. The federal government's role in forestry focusses on trade and investment, national statistics, science and technology, aboriginal affairs, environmental regulations and international relations. Another federal agency, Parks Canada, has a legislated mandate to maintain the ecological integrity of representative ecosystems in its system. The CFS works in partnership with forest stewards to protect forests, but operational forest management, including pest management, is the responsibility of the provincial and territorial governments. The different levels of government share responsibilities and cooperate on S\&T, industrial and regional development, the environment and other related forestry matters.

The CFS, the principal Canadian forest research organization, addresses issues of sustainability by providing sciencebased information to provincial and territorial governments, private sector forest managers, other federal departments and agencies, aboriginal forest organizations, non-governmental organizations and the interested public. As a national organization, the CFS is particularly well-suited to provide research on forest pest problems as these problems typically are of a long-term nature and occur across provincial and ecological boundaries. CFS has particular abilities to assess the health of forests and to integrate information from forest health assessments with management goals of ecological integrity. The expertise provides the scientific basis for definition of levels of disturbance that promote sustainable forest ecosystems and prediction of disturbance impacts from natural and humancaused events.

The CFS works cooperatively with other federal departments and agencies responsible for forest issues and with regulatory mandates affecting the forest sector. The PMRA of Health Canada is responsible for providing safe use of pesticides while minimizing risks to the environment and to human health. The CFS links forest pest issues through the mechanism of Federal - Provincial Memoranda of Agreement or Understanding. The CFS collaborates with the CFIA in the detection and identification of invasive pests. These organizations address issues of:

- understanding and quantifying the effects of pests on forest ecosystems,

- maintaining the infrastructure when damage from pests are minimal,

- maintaining staffing levels to ensure continuity, and

- establishment of sources of pest management products for sudden, periodic and localized use.

Workshop participants agreed on these general principles of integrating pest management with forest management and the key role for scientific research. They also agreed that the CFS play the major role as a national coordinating organization and a provider of knowledge required to plan and implement pest management activities.

\section{Elements of a Pest Management Strategy}

Workshop participants agreed that a sustainable forest exhibiting ecological integrity requires a systems approach to pest management. Pest management planning and procedures in an overall resource management strategy based on good science and supported by society is the path to this goal. All Canadian forest ecosystems - whether commercial forests managed for fibre, urban forests, or conservation forests managed for recreation, spiritual values and non-timber forest products - require pest management to attain sustainability. Basic and applied research over the short and long term applied at various scales is necessary to manage pest impacts sustainably. The primary approach should be the use of preventative tactics including the enhancement of natural controls, silvicultural methods and development of plant resistance. Failing this, remedial actions including use of pesticides and augmentation of predators and parasites should be used. Managers must accept that the maintenance of resilience at the landscape level may require severe disturbance for stand renewal.

Forest structures that are more resilient to insect and disease disturbance will be a long time coming, therefore, we need a strategy for insect and disease disturbance over the next 20-30 years implemented at landscape and stand levels to build resilience into the managed forest. Current conditions reflect harvesting and management decisions of the last century, consequently management decisions taken now will take several decades to be evident. Parks Canada has already adopted this strategy of ecological integrity, which has the goal of sustainability, but with little emphasis on the social and economic outcomes that CFS supports.

Elements of a broad sustainability approach to pest management include:

- the importance of understanding the dynamics of forest ecosystems,

- the importance of knowing which pests drive disturbance,

- determination of acceptable thresholds of losses from pests,

- sensitive detecting, monitoring and forecasting techniques for native/invasive pests,

- an integrated approach to pest problems which is adaptable and flexible, and

- commitment to best practices in pest management by government, industry and the public.

Workshop participants emphasized the need for forest pest management as an essential component of sustainable forest management incorporating ecological integrity. Specific themes and goals were identified for a forest pest management strategy:

1) A forest pest management strategy requires a sciencebased, multi-disciplinary, multi-stakeholder approach that is proactive, on-going and adequately financed.

2) New tools for management of diseases and insects that are becoming of greater concern in plantation and other managed forests. Reliance on a finite wood supply will create the need to protect commercial forests and to develop new 
tools for protection, particularly as we move toward intensive forest management on a more limited and controlled landbase.

3) Decision support systems for the forest manager based on tested methods so that decisions on interventions can be based on approaches that are biologically, economically and politically sound. The degree to which pest management is necessary depends on economic thresholds which, in turn, are determined by the level of management practised. In an intensively managed forest a significant investment is made over the life of that forest; consequently, timber losses are more critical than in less-intensively managed forests. In a naturally regenerated forest with less investment, greater losses are acceptable and a more "hands-off" approach to pest management is justified. The vast, forested landbase in Canada supporting rural populations requires effective management of resources to ensure employment.

4) Implementation of an integrated strategy to manage pests, therefore, is predicated on a prioritizing of forest land among different uses and, consequently, with different intensities of management. Such a division might have intensively managed forests primary for fibre production, extensively managed forests primarily for non-timber uses with fibre as a secondary value, and conservation forests where the primary value is protection.

5) Science-based decisions will require enhanced knowledge of pest biology, taxonomy and ecology, monitoring of pest populations, innovative control methods, knowledge of action thresholds, and integration with the social, economic and physical realities of the forest.

6) The urban forest is becoming more of a public issue currently driven by the issue of invasive pests and these forests are where over $80 \%$ of our population lives. The public demands healthy forests and the tools to ensure they remain so.

7) Climate change will result in unpredictable changes in pest problems with important consequences for pest management. It is critical that we monitor large-scale changes in the behaviour of pest populations to anticipate and adapt to new conditions. Consequently, it is important to have a selection of methods available and the knowledge available to integrate these methods effectively.

The vision for our forests is one that incorporates the goals of sustainability supported by a concerned and articulate public, of ecologically healthy forests on public and private lands providing fibre yields for the economy, preserving a range of forest values and demonstrating that we are living in harmony with our forest environment. Public demand for environmental approaches to forest management and pest management will be the way we do business in the future.

\section{Acknowledgements}

The author would like to acknowledge the many people who contributed to the Pest Management Workshop, and particularly in the preparation and review of this article: Anthony Hopkin, Ben Moody, Hans Ottens, Guy Smith, and Vince Nealis. 